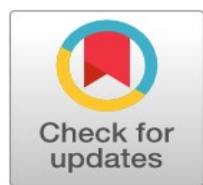

ORIGINAL CONTRIBUTION

\title{
An investigation of in flight service quality of Chinese carriers in Australia-China market
}

\author{
Hongwei Jiang ${ }^{1 *}$, Chrystal Zhang ${ }^{2}$, Gan Xiao ${ }^{3}$, He Ren ${ }^{4}$, Xi Chen ${ }^{5}$ \\ ${ }^{1}$ RMIT University, Melbourne, Australia \\ ${ }^{2}$ Swinburne University of Technology, Melbourne, Australia \\ 3 Shanghai Jiao Tong University, Shanghai, China \\ 4, 5 The Commercial Aircraft Corporation of China, Shanghai, China
}

\author{
Index Terms \\ Airline service quality \\ In-flight service quality \\ Passenger perception \\ Chinese airlines \\ Received: 15 January 2017 \\ Accepted: 4 February 2017 \\ Published: 21 April 2017
}

\begin{abstract}
Provision of high quality service in a competitive environment is a core competitive advantage for airline's profitability and sustainable growth. The purpose of this paper is to investigate the in-flight service quality of major Chinese airlines including Air China, China Southern Airlines, China Eastern Airlines, and Sichuan Airlines operating between Australia and China. Surveys were distributed to passengers at Melbourne airport. The results show that there are no significant differences between the in-flight service quality of these four carriers. Lower air fare remains the most significant factor influencing passengers' airline preferences. The findings suggest that airlines should consider improving service quality to gain competitive advantages rather than providing cheaper air tickets.
\end{abstract}

(C) 2017 The Author(s). Published by TAF Publishing.

\section{INTRODUCTION \\ Background}

China has become Australia's largest trading partner as well as the biggest export market and the largest source of imports. For the past five years, trade between Australia and China has exceeded $\$ 500$ billion in value, of which more than $\$ 300$ billion have been exported from Australia to China (Huang, 2014). China is also considered the second largest inbound tourism market for Australia, surpassed only by New Zealand (Rigg, 2015). The year 2013-2014 saw around 769,000 Chinese travellers visiting Australia, a three-fold increase from a decade ago (Australian $\mathrm{Bu}$ reau of Statistics, 2014). To keep up with demands, the initial two airlines providing direct services between the two countries, Qantas Airways and Air China, have more than doubled to the current five, including additions of China Eastern, China Southern and Sichuan Airlines to the competition. A recently revised bilateral air service agreement between the two countries has enabled an immediate increase in capacity by 18 per cent to 22,000 seats per week for one-way flights, with more to follow in stages over the next few years, thus opening a door to allow more carriers to enter the market.

Ostrowski, O'Brien \& Gordon, (1993) it is reported that Xiamen Airlines and Shandong Airlines are both interested in the market and intend to launch their services soon. Qantas Airways has long upheld a consistently good reputation regarding its service quality, and is one of the best airlines in the world (Skytrax, 2014). Therefore, it has now become very important for Chinese airlines to improve their ser-

\footnotetext{
*Corresponding author: Hongwei Jiang

†Email: george.jiang@rmit.edu.au
} 
vice quality in order to gain competitive advantages in the Australia-China market.

\section{Objectives and Research Gap}

There is a growing interest in research relating to service quality and customer satisfaction in the airline industry as delivery of high service quality is essential to an airline's survival and competitiveness (Park, Robertson $\& \mathrm{Wu}, 2004)$. In reviewing the lessons learned over the past decade from service quality research, there has been a strong indication that improvements in service quality increased profits yielded by new and loyal customers. Research has indicated that companies offering superior service are able to charge eight per cent higher for their product (Gale, 1992) and to achieve higher-than-average market share growth and profitability (Buzzell \& Gale, 1987).

The in-flight service quality is an integral element of airline service quality. However, there is no previous research examining the in-flight service provided by the four Chinese air carriers for the route from Australia to China. The aims of the paper are: (1) to investigate the differences in in-flight service quality among four Chinese airlines from passengers' perceptions; (2) to provide information to passengers when choosing an airline with higher service quality; (3) to provide information to airline managers in order to reduce the gaps of service quality; (4) to investigate the importance of price and its role for passengers to choose an airline, in the hopes that it would help China's airlines direct their focus from offering cheaper airfare to offering higher quality service.

\section{Service Quality in Airline Industry}

One of the characteristics of airlines is homogeneity of products, namely, airlines' product offerings are essentially identical as the core function of an airline is to carry the traffic from one destination to the next. They use identical aircrafts with identical technology and compete for higher service quality, which becomes a significant distinguishing factor between airlines. Service quality can be defined as a consumer's overall impression of the relative efficiency of an organisation and its services (Park, et al., 2004).

Two main conceptualizations of service quality exist. One is based on a disconfirmation approach, and the other on a performance-only approach (An \& Noh, 2009). Although Servqual has been widely applied in a variety of industries, some criticism of the Servqual model exists in the literature of the disconfirmation approach (An \& Noh, 2009). Cronin Jr \& Taylor (1992) and Taylor (1993) state that 'a performance-based measure of service quality might be an improved means of measuring the service quality construct' because it only measures the perception of customers' experience and it is a theoretically valid way of measuring perceived quality (Grönroos, 1984). Many studies have addressed airline service quality issues which are partially covered in-flight service quality. Elliott \& Roach (1993) selected food quality, seat and leg room, and inflight service as part of the criteria on which airline service quality is evaluated.

Designed a 'Service Quality Evaluation of Flight' section for the questionnaire, in which 9 out of 16 elements were related to in-flight services. The results led to the conclusion that there is still much room for improvement for air carriers in terms of their service quality. Chang \& Yeh (2002) used on-board comfort, airline employees, reliability of service, convenience of service and handling of abnormal conditions for the evaluation of the service quality of Taiwan's domestic airlines. Fifteen service attributes embodied by these five categories were selected within some attributes of in-flight services. The evaluation outcomes aided airlines in identifying their internal and external competitive advantages relative to their competitors (Chen \& Chang, 2005).

Park et al. (2004) selected 22 airline service quality measurement items, including in-flight service items, to measure service expectations and service perceptions on a Korean case study. The results showed that service value, passenger satisfaction and airline image exerted a direct impact upon passengers' decision making processes. Gilbert \& Wong (2003) adapted the SERVQUAL instrument for their study and developed a 26-item questionnaire, which contained 14 in-flight service items corresponding to reliability, assurance, facilities, employees, flight patterns, customisation and responsiveness. They measured and compared the differences between passengers' expectations of the desired airline service quality.

Similarly, Pakdil \& Aydin (2007) designed a questionnaire based on the SERVQUAL, with 35 items in 8 dimensions: tangibles, responsiveness, reliability and assurance, empathy, flight patterns, employees, availability and image. Nearly half of the items were relative to in-flight service and were used to measure Turkish airline service quality. Moreover, Chou, Liu, Huang, Yih \& Han (2011) also evaluated airline service quality by applying SERVQUAL method. For the questionnaire, they classified 28 airline service attributes, which were involved in-flight service attributes, into five dimensions, just as the first five of Pakdil \& Ay- 
din (2007) questionnaire. Few studies analysed in-flight service quality independently which has provided a basic concept of in-flight service quality.

Chen \& Chang (2005) separated in-flight service from airline service and examined it from a process perspective by first examining the gap between passengers' expectations and the actual service received, and the gaps associated with passenger service expectations, perceptions of these expectations by frontline managers and employees of a Taiwanese airline. Importance-performance analysis was then used to construct service attribute evaluation maps to identify areas for improvement. They found that gaps did exist and passengers considered the tangibles dimension more important when evaluating in-flight service quality. Comprehensive research about airline in-flight entertainment had been done by Alamdari (1999). Based on the passenger survey and other literature, Alamdari (1999) summarised that in-flight entertainment is not a primary factor affecting passenger choice and passengers do not appear to be prepared to pay for it.

However, in the future, in-flight entertainment will become part of expected product features in all classes as a competitive factor between airline companies. Airlines should focus on the reliability of in-flight entertainment to preserve their image in passengers' minds. An \& Noh (2009) investigated the impact of the in-flight service quality on airline customer satisfaction and loyalty. The results indicated that the recognition of in-flight service quality is somewhat different according to the customer seat class. The findings implied that airline companies' in-flight service should have different delivery strategies based on the customer seat class. Chen, Tseng \& Lin (2011) ranked 5 Taiwanese airlines in order to evaluate customers' perceptions of in-flight service quality.

They emphasised a proposed model, Grey-fuzzy approach, and applied it to deal with the vagueness and uncertainty of in-flight service quality. Quality is one of the most important factors influencing a customer's consumption decisions (Anderson \& Zeithaml, 1984). Increased emphasis has been placed on the continued development of knowledge related to service organizations, particularly the role service quality plays in creating satisfied and loyal customers (Ostrowski et al., 1993; Na Ayutthaya, Tuntivivat \& Prasertsin, 2016). It has strategic benefits of contributing to market-share and return on investment (Phillips, Chang \& Buzzell, 1983) as well as lowering manufacturing costs and improving productivity (Garvin, 1983). High quality customer service can be the differentiating factor between a business and its competitor.

\section{METHODOLOGY Questionnaire Design}

To carry out this research, a list of services that make up the typical service offered in the airline industry was first drawn up (Oyewole, 2001). Questionnaires were designed in light of previous literature (Chang \& Yeh, 2002; Chen \& Chang, 2005; Park et al., 2004; An \& Noh, 2009; Chen et al., 2011).

The questionnaire was divided into three parts, the first of which contained questions regarding respondents' sociodemographic characteristics including age, gender, education, nationality and income. Since consumers' needs, preferences and personalization are often associated with demographic factors (Kotler, 2000), demographic characteristics related to in-flight service (Cheaosakul, 2004) and preference factors are considered. The second part inquired after passengers' flight information including purpose of travel, travel frequency, cabin class, air ticket booking channel, 'airline flew with', and 'most important factor when choosing an airline'.

The third part is composed of 34 questions regarding perceptions of in-flight service quality measured by a fivepoint Likert scale with anchors of "Strongly unsatisfied" to "Strongly satisfied". In considering the distribution of passengers' nationality, the questionnaire was prepared in two versions: English and Chinese.

\section{Sample and Data Collection}

The target population for this study consisted of passengers who had travelled from Australia to China by using four Chinese airlines-Air China, China Southern Airlines (2014), China Eastern Airlines, and Sichuan Airlines. Primary data were gathered directly from passengers, and a survey was conducted from 15 September to 2 October 2014. Participants of this study included 200 passengers at Melbourne Airport.

The survey was timed to coincide with the opening hours of the airports. It was conducted between Monday and Sunday from morning flights to night flights to minimise any biases of the results. 200 questionnaires were randomly distributed to passengers waiting at check-in counters, boarding gates of the four airlines and departure lounges at the airports. Prior to starting the survey, passengers confirmed that they have flown from Australia to China with one of the four Chinese airlines in the last 12 months, and 145 questionnaires were verified as useful. 


\section{Statistical Analysis Method}

The statistical program package SPSS 22 is used for data analysis in the study. Descriptive statistics are used to describe the mean, variance and the categories and characteristics of the data. Exploratory factor analysis (EFA) was performed to support the issues of dimensionality, convergence, and discriminant validity (Gerbing \& Anderson, 1988). Analysis of variance (ANOVA) was used to help understand the differences between the four airlines in this study.

\section{RESULT S}

\section{Demographic Profile of Respondents}

Table 1 shows the demographic information of the subjects. Respondents are roughly evenly split between males
(49.7\%) and females (50.3\%). The percentages of age group in order are 18-30 (54.5\%), 41-50 (17.2\%), 31-40 (11.7\%), 51-60 (10.3\%), under 18 (4.1\%) and 61 and over (2.1\%). This indicated younger travelers are active in the Australian market-China air route. A large portion of respondents are Asians (77.2\%), while $21.4 \%$ are Australians and only $1.4 \%$ are Europeans. In the dimension of annual income, $44.1 \%$ of the respondents earn less than $A \$ 20,000$. There are $21.4 \%$ private-sector employees, $13.8 \%$ private business owners and others respectively, $8.3 \%$ retired people and $2.8 \%$ government employees. In terms of education status, 69 respondents hold bachelor degrees (47.6\%), followed by 31 holding postgraduate degree $(21.4 \%), 27$ holding senior high or below degree $(18.6 \%)$ and the rest who obtained diplomas (12.4\%).

TABLE 1. Demographic data $(N=145)$

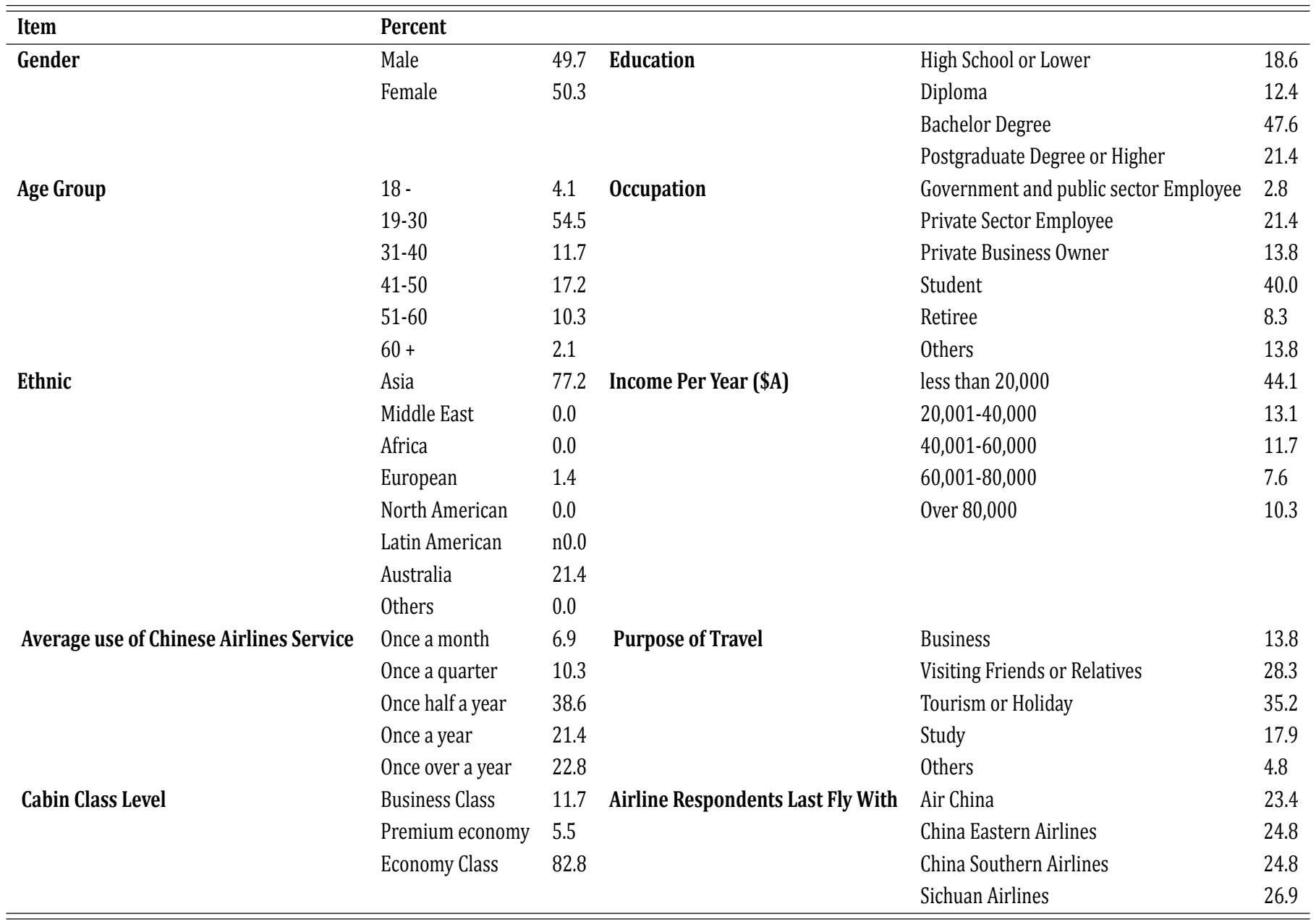

\section{Factor Analysis}

To assess the dimensionality of the service item scale, Explore Factor Analysis was performed on the 34 items using the Principal Factor/Component (PF) method, followed by Varimax rotation. Table 2 shows the results of the factor analysis test for the 34 variables. The Kaiser-Meyer-Olkin 
(KMO) value, which is a measure of sampling adequacy, was found to be 0.883 , suggesting that the factor analysis had proceeded correctly and that the sample was adequate. The results of the Bartlett's Test of Sphericity were also significant, which indicated that the factor analysis processes were correct and suitable for testing multidimensionality. All of the items loaded more than 0.50 which met the requirement of a factor loading of 0.50 to be significant for a sample size of 120 or greater (Hair, Anderson, Tatham \& Black, 1998). Four factors were extracted which together accounted for 83 percent of the variance. The factors were labelled as Cabin Configuration (Factor 1), In-flight Entertainment Services (Factor 2), Meals/Snacks (Factor 3) and Flight Attendants' service (Factor 4).

Cronbach's Alpha reliability test was used on the dimensions of perception and expectation to determine the reliability of the data. The results in Table 2 indicate that the Cronbach's Alpha values are all above 0.90, which showed acceptable reliability. Nunnally \& Ira (1994) suggested that a minimum of 0.70 would be an acceptable level.

TABLE 2 . Factor analysis

\begin{tabular}{|c|c|c|c|c|c|c|}
\hline \multirow[t]{2}{*}{ Item } & \multirow[t]{2}{*}{ Standardized Loading } & \multirow[b]{2}{*}{ Factor 1} & \multirow[b]{2}{*}{ Factor 2} & \multirow[b]{2}{*}{ Factor 3} & \multirow[b]{2}{*}{ Factor 4} & \multirow[t]{2}{*}{ Variance Explained } \\
\hline & & & & & & \\
\hline \multicolumn{7}{|c|}{ Cabin Configuration } \\
\hline Q1 & Cabin equipment condition & 0.68 & & & & 0.46 \\
\hline Q2 & Seating comfort & 0.89 & & & & 0.78 \\
\hline Q3 & Arms of the seat & 0.87 & & & & 0.76 \\
\hline Q4 & Backrest angle & 0.80 & & & & 0.65 \\
\hline Q5 & Seat space and legroom & 0.81 & & & & 0.66 \\
\hline Q6 & Design of tray table & 0.67 & & & & 0.45 \\
\hline Q7 & Lighting condition & 0.52 & & & & 0.27 \\
\hline Q8 & Supply of sockets & 0.51 & & & & 0.26 \\
\hline Q9 & Restroom cleanness & 0.60 & & & & 0.35 \\
\hline \multicolumn{7}{|c|}{ Entertainment Services } \\
\hline Q10 & Screen size & & 0.86 & & & 0.74 \\
\hline Q11 & Operability of the system & & 0.85 & & & 0.72 \\
\hline Q12 & Audio quality & & 0.88 & & & 0.78 \\
\hline Q13 & Image quality & & 0.91 & & & 0.82 \\
\hline Q14 & Variety of games & & 0.85 & & & 0.73 \\
\hline Q15 & Movies update & & 0.83 & & & 0.89 \\
\hline Q16 & Flight information & & 0.67 & & & 0.44 \\
\hline Q17 & Variety of newspapers and magazines & & 0.67 & & & 0.45 \\
\hline Q18 & Duty free sales & & 0.57 & & & 0.32 \\
\hline \multicolumn{7}{|l|}{ Meals/Snacks } \\
\hline Q19 & Supply of towels & & & 0.68 & & 0.47 \\
\hline Q20 & Food options & & & 0.92 & & 0.85 \\
\hline Q21 & Food quality & & & 0.91 & & 0.83 \\
\hline Q22 & Presentation of food & & & 0.90 & & 0.81 \\
\hline Q23 & Special request (e.g. kids meal, vegetarian etc.) & & & 0.81 & & 0.65 \\
\hline Q24 & Alcoholic beverage & & & 0.78 & & 0.61 \\
\hline Q25 & Non-alcoholic beverage & & & 0.73 & & 0.53 \\
\hline Q26 & Speed of meals/snack service & & & 0.73 & & 0.53 \\
\hline \multicolumn{7}{|c|}{ Flight Attendants' Service } \\
\hline Q27 & Clarity of cabin announcement & & & & 0.67 & 0.45 \\
\hline Q28 & Appearance of flight attendants & & & & 0.79 & 0.63 \\
\hline Q29 & Promptness of service & & & & 0.84 & 0.7 \\
\hline Q30 & Proactivity of flight attendants & & & & 0.85 & 0.72 \\
\hline Q31 & Courtesy of flight attendants & & & & 0.87 & 0.75 \\
\hline Q32 & Sufficiency of flight attendants' knowledge to answer questions & & & & 0.82 & 0.68 \\
\hline Q33 & Consideration for passengers' needs and interests & & & & 0.82 & 0.67 \\
\hline Q34 & Flight attendants' ability to handle customer complaints & & & & 0.79 & 0.63 \\
\hline Cronbach's Alpha & & 0.901 & 0.938 & 0.94 & 0.935 & \\
\hline
\end{tabular}

\section{Passengers' Perception of In-flight Service Quality}

Table 3 reports the mean and the standard deviation of 34 items of the questionnaire.

\section{Cabin configuration}

Regarding each attribute in Table 3, Air China (2014) is in the highest rank of backrest angle (mean $=3.41$ ) and lighting condition (mean $=3.94)$. Respondents prefer the cabin equipment condition (mean $=3.72$ ), seat arms (mean $=3.42$ ) and supply of sockets (mean $=3.33$ ) on the flight operated by China Eastern. Seating comfort (mean $=3.33$ ), seat space and legroom (mean $=3.26)$, design of tray table $($ mean $=3.54)$ and restroom cleanness $($ mean $=3.72)$ are recognised for Sichuan Airlines. The overall perception of 
the cabin configuration from highest to lowest is: Sichuan Airlines, China Eastern, Air China and China Southern.

\section{Entertainment services}

As shown in Table 3, all attributes relative to in-flight entertainment systems are ranked higher by respondents who flew with China Eastern. Sichuan Airlines and Air china provided a greater variety of newspapers and magazines $($ mean $=3.36)$ and higher duty free sales (mean $=3.62)$ respectively. As a result, China Eastern achieved the highest score among four Chinese airlines in terms of entertainment services (mean $=3.58$ ), followed by Air China (mean $=3.39)$, China Southern (mean = 3.36) and Sichuan Airlines $($ mean $=3.34)$.

\section{Meals/Snacks}

Sichuan Airlines is rated highest in all attributes of meals/snacks services, excluding supply of towels and alcoholic beverage. These two attributes are better provided by China Eastern, with mean values of 3.75 and 3.56 re- spectively. Consequently, the rank order in this section is: Sichuan Airlines (mean $=3.59$ ), China Eastern (mean = 3.56), China Southern (mean $=3.46$ ) and Air China (mean $=3.34$ ).

\section{Flight attendants' service}

Table 3 indicates that passengers' perceptions of the best aspect of in-flight services is the flight attendants' service, because the mean averages of each airline in this section are distinctly higher compared to other sections. The rank in order is: China Eastern (mean $=4.06$ ), Air China (mean = 3.96), China Southern (mean $=3.81$ ) and Sichuan Airlines (mean $=3.75$ ). In terms of each attribute, most of the highest mean values are above 4 which signify passengers are satisfied with them. Air China has the highest ranking for the appearance of its flight attendants (mean $=4.26$ ) and the sufficiency of flight attendants' knowledge for answering passengers' questions (mean $=4.06$ ). The other attributes are better perceived by passengers who flew with China Eastern.

TABLE 3 . Mean and standard deviation statistics

\begin{tabular}{|c|c|c|c|c|c|c|c|c|c|}
\hline & & \multicolumn{2}{|c|}{ Air China } & \multicolumn{2}{|c|}{ China Eastern } & \multicolumn{2}{|c|}{ China Southern } & \multicolumn{2}{|c|}{ Sichuan Airlines } \\
\hline & & Mean & SD & Mean & SD & Mean & SD & Mean & SD \\
\hline \multirow[t]{10}{*}{ Cabin Configuration } & Q1 & 3.71 & 0.94 & 3.72 & 0.94 & 3.39 & 0.84 & 3.69 & 1.12 \\
\hline & Q2 & 3.26 & 0.99 & 3.28 & 1.19 & 3.08 & 1 & 3.33 & 1.14 \\
\hline & Q3 & 3.26 & 0.99 & 3.42 & 0.94 & 3.03 & 0.97 & 3.36 & 1.07 \\
\hline & Q4 & 3.41 & 1.02 & 3.36 & 1.02 & 2.94 & 1.12 & 3.38 & 1.07 \\
\hline & Q5 & 2.97 & 1.22 & 2.92 & 1.23 & 2.83 & 1.11 & 3.26 & 1.15 \\
\hline & Q6 & 3.5 & 0.99 & 3.47 & 0.81 & 3.42 & 0.94 & 3.54 & 1.14 \\
\hline & Q7 & 3.94 & 0.89 & 3.78 & 0.87 & 3.86 & 0.76 & 3.67 & 0.79 \\
\hline & Q8 & 2.74 & 1.33 & 3.33 & 1.29 & 3.14 & 1.22 & 3.31 & 1.17 \\
\hline & Q9 & 3.47 & 0.93 & 3.56 & 1.05 & 3.47 & 0.81 & 3.72 & 0.96 \\
\hline & & 3.36 & & 3.43 & & 3.24 & & 3.47 & \\
\hline \multirow{10}{*}{ Entertainment Services } & Q10 & 3.5 & 0.99 & 3.67 & 1.12 & 3.42 & 0.84 & 3.36 & 0.84 \\
\hline & Q11 & 3.29 & 1.12 & 3.69 & 1.14 & 3.5 & 0.91 & 3.44 & 0.94 \\
\hline & Q12 & 3.44 & 1.13 & 3.64 & 1.07 & 3.33 & 1.01 & 3.33 & 0.84 \\
\hline & Q13 & 3.41 & 1.13 & 3.67 & 1.07 & 3.47 & 1.03 & 3.28 & 0.89 \\
\hline & Q14 & 3.03 & 1.11 & 3.33 & 1.15 & 3.06 & 1.22 & 3 & 1 \\
\hline & Q15 & 3.24 & 1.13 & 3.28 & 1.14 & 3.19 & 1.28 & 3.18 & 1 \\
\hline & Q16 & 3.79 & 1.04 & 4 & 0.79 & 3.64 & 1.07 & 3.9 & 0.75 \\
\hline & Q17 & 3.18 & 1.09 & 3.33 & 1.17 & 3.25 & 1.08 & 3.36 & 0.9 \\
\hline & Q18 & 3.62 & 0.95 & 3.61 & 0.96 & 3.39 & 0.93 & 3.21 & 1.03 \\
\hline & & 3.39 & & 3.58 & & 3.36 & & 3.34 & \\
\hline \multirow[t]{9}{*}{ Meals/Snacks } & Q19 & 3.53 & 1.08 & 3.75 & 1.08 & 3.53 & 1.11 & 3.54 & 0.82 \\
\hline & Q20 & 3.09 & 1.16 & 3.5 & 1.08 & 3.39 & 1.02 & 3.51 & 0.91 \\
\hline & Q21 & 3.15 & 1.16 & 3.42 & 1.13 & 3.42 & 1.16 & 3.56 & 0.91 \\
\hline & Q22 & 3.15 & 1.18 & 3.39 & 1.02 & 3.31 & 1.06 & 3.64 & 0.96 \\
\hline & Q23 & 3.24 & 1.21 & 3.36 & 1.07 & 3.39 & 1.15 & 3.46 & 1 \\
\hline & Q24 & 3.26 & 1.14 & 3.56 & 1.03 & 3.39 & 0.84 & 3.41 & 0.88 \\
\hline & Q25 & 3.65 & 1.07 & 3.64 & 1.05 & 3.61 & 0.87 & 3.69 & 0.77 \\
\hline & Q26 & 3.65 & 1.13 & 3.86 & 0.99 & 3.67 & 0.79 & 3.87 & 0.83 \\
\hline & & 3.34 & & 3.56 & & 3.46 & & 3.59 & \\
\hline \multirow[t]{9}{*}{ Flight Attendants' Service } & Q27 & 3.76 & 0.89 & 4 & 0.96 & 3.86 & 0.9 & 3.64 & 0.93 \\
\hline & Q28 & 4.26 & 0.62 & 4.22 & 0.72 & 4.06 & 0.79 & 3.95 & 0.72 \\
\hline & Q29 & 3.88 & 0.81 & 4.14 & 0.76 & 3.94 & 0.86 & 3.79 & 0.8 \\
\hline & Q30 & 3.91 & 0.93 & 4.14 & 0.8 & 3.81 & 0.86 & 3.82 & 0.79 \\
\hline & Q31 & 4.12 & 0.73 & 4.19 & 0.67 & 3.94 & 0.79 & 3.82 & 0.85 \\
\hline & Q32 & 4.06 & 0.78 & 3.89 & 1.04 & 3.72 & 0.94 & 3.72 & 0.76 \\
\hline & Q33 & 3.79 & 0.98 & 3.86 & 1.13 & 3.61 & 1.1 & 3.56 & 0.97 \\
\hline & Q34 & 3.88 & 0.98 & 4.03 & 0.94 & 3.5 & 1 & 3.69 & 0.89 \\
\hline & & 3.96 & & 4.06 & & 3.81 & & 3.75 & \\
\hline
\end{tabular}




\section{ANOVA Test}

The ANOVA were performed to test if there are any differences in service quality between four airlines, between "nationalities", between "travel purpose" and "seat classes". Ta- bles 4, 5, 6 and 7 report that there are no significant differences between selected airlines, nationalities and travel purposes ( $p$-values of all factors are more than 0.05 ).

TABLE 4 . ANOVA between airlines

\begin{tabular}{lccc}
\hline \hline Dimension of Service Quality & F & $\boldsymbol{p}$-values & Significant Difference \\
\hline Cabin Configuration & 1.952 & 0.245 & No \\
Entertainment Services & 1.531 & 0.308 & No \\
Meals/Snacks & 1.373 & 0.375 & No \\
Flight Attendants' service & 2.72 & 0.074 & No \\
\hline \hline
\end{tabular}

TABLE 5 . ANOVA between nationalities (Asia, Australia, and others)

\begin{tabular}{llllllllllllll}
\hline \hline & \multicolumn{1}{l}{ Air China } & \multicolumn{4}{c}{ China Eastern } & \multicolumn{4}{c}{ China Southern } & \multicolumn{3}{c}{ Sichuan Airlines } \\
\hline & $\mathrm{F}$ & $\mathrm{P}$ & Dif & $\mathrm{F}$ & $\mathrm{F}$ & $\mathrm{P}$ & $\mathrm{F}$ & $\mathrm{P}$ & Dif & $\mathrm{F}$ & $\mathrm{P}$ & Dif \\
\hline Cabin Configuration & 0.463 & 0.604 & No & 1.973 & 0.268 & No & 0.656 & 0.538 & No & 0.54 & 0.6 & No \\
Entertainment Services & 0.418 & 0.58 & No & 2.767 & 0.085 & No & 0.317 & 0.641 & No & 0.33 & 0.645 & No \\
Meals/Snacks & 1.747 & 0.323 & No & 1.68 & 0.339 & No & 0.393 & 0.592 & No & 0.062 & 0.838 & No \\
Flight Attendants' Service & 1.893 & 0.267 & No & 2.638 & 0.205 & No & 0.491 & 0.64 & No & 0.233 & 0.724 & No \\
\hline \hline
\end{tabular}

TABLE 6 . ANOVA between purposes of travel (Holiday, VFR, business and others)

\begin{tabular}{llllllllllllll}
\hline \hline & \multicolumn{1}{l}{ Air China } & \multicolumn{4}{c}{ China Eastern } & \multicolumn{3}{c}{ China Southern } & \multicolumn{3}{c}{ Sichuan Airlines } \\
\hline & F & P & Dif & F & F & P & F & P & Dif & F & P & Dif \\
\hline Cabin Configuration & 1.578 & 0.298 & No & 1.087 & 0.446 & No & 1.645 & 0.279 & No & 0.672 & 0.628 & No \\
Entertainment Services & 0.618 & 0.668 & No & 0.923 & 0.529 & No & 1.071 & 0.467 & No & 1.566 & 0.265 & No \\
Meals/Snacks & 0.525 & 0.73 & No & 0.293 & 0.869 & No & 1.23 & 0.366 & No & 1.563 & 0.285 & No \\
Flight Attendants' Service & 1.699 & 0.299 & No & 0.658 & 0.637 & No & 1.676 & 0.197 & No & 0.454 & 0.727 & No \\
\hline \hline
\end{tabular}

Regarding seat classes (business vs economy), Table 7 reports no significant differences across all four factors for Air China and Sichuan Airlines; significant differences across two factors (cabin configuration and meal/snacks) for China Eastern; and one factor (meals/snacks) has significant difference for China Southern. The premium economy class is only operated by China Southern, therefore it is not comparable against other airlines. $11.7 \%$ of responses were from passengers flying business class and $82.8 \%$ from passengers flying economy class. Mean results are displayed in Table 8 and Table 9 for both classes.

TABLE 7. ANOVA between seat classes (Business class and economy class)

\begin{tabular}{llllllllllllll}
\hline \hline & Air China & \multicolumn{4}{c}{ China Eastern } & \multicolumn{4}{c}{ China Southern } & \multicolumn{3}{c}{ Sichuan Airlines } \\
\hline & F & P & Dif & F & F & P & F & P & Dif & F & P & Dif \\
\hline Cabin Configuration & 1.85 & 2.34 & No & 7.21 & 0.02 & Yes & 3.2 & 0.15 & No & 0.81 & 0.52 & No \\
Entertainment Services & 2.29 & 0.22 & No & 2.05 & 0.29 & No & 1.21 & 0.39 & No & 3.6 & 0.2 & No \\
Meals/Snacks & 1.4 & 0.41 & No & 5.63 & 0.02 & Yes & 5.48 & 0.02 & Yes & 3.62 & 0.46 & No \\
Flight Attendants' Service & 3.34 & 0.19 & No & 2.89 & 0.15 & No & 3.29 & 0.06 & No & 2.21 & 0.26 & No \\
\hline \hline
\end{tabular}

\section{Business class}

Table 8 shows that China Eastern gained the highest ratings in terms of in-flight service across all factors: cabin configuration $($ mean $=4.36)$, entertainment services $($ mean $=$
3.98), meals/snacks (mean $=4.45)$ and flight attendants' service (mean $=4.58)$. These results reflect the highest overall rating for business classes across airlines (mean = 4.34), followed by China Southern, Sichuan Airlines and then Air China. 
TABLE 8 . Statistics of business class

\begin{tabular}{lllll}
\hline \hline Business Class (Mean values) & & & & \\
\hline & Air China & China Eastern & China Southern & Sichuan Airlines \\
\hline Cabin Configuration & 3.33 & 4.36 & 3.37 & 3.47 \\
Entertainment Services & 2.44 & 3.98 & 3.27 & 2.83 \\
Meals/Snacks & 2.5 & 4.45 & 4.02 & 3.22 \\
Flight Attendants' Service & 3.25 & 4.58 & 4.29 & 3.38 \\
Mean Average & 2.88 & 4.34 & 3.74 & 3.23 \\
\hline \hline
\end{tabular}

\section{Economy class}

Results for economy class however are dramatically different. Respondents who flew with Sichuan Airlines have better perceptions of cabin configuration (mean $=3.47$ ) and meals/snacks (mean $=3.63$ ) in economy class compared to other airlines, and thus gained the overall highest rating (mean $=3.57$ ). According to the mean values for en- tertainment services, China Eastern is perceived as the best provider among the four Chinese airlines (mean $=3.52$ ). In addition, China Eastern and Air China are tied in first place in terms of their flight attendants' service (mean $=3.98$ ). Table 9 also indicates that respondents who flew economy class have poorer perceptions of the in-flight service quality of China Southern.

TABLE 9. Statistics of economy class

\begin{tabular}{lllll}
\hline \hline Economy Class (Mean values) & & & & \\
\hline & Air China & China Eastern & China Southern & Sichuan Airlines \\
\hline Cabin Configuration & 3.36 & 3.28 & 3.14 & 3.47 \\
Entertainment Services & 3.42 & 3.52 & 3.33 & 3.4 \\
Meals/Snacks & 3.36 & 3.42 & 3.23 & 3.63 \\
Flight Attendants' Service & 3.98 & 3.98 & 3.65 & 3.79 \\
Mean Average & 3.53 & 3.55 & 3.34 & 3.57 \\
\hline \hline
\end{tabular}

\section{Reasons for Choosing an Airline}

Although air fare is not part of the four factors as it does not contribute to in-flight service quality, price is one of the most important factors that passengers consider when choosing an airline.

In order to investigate how prices affected passengers' choices, a separate question is designed in addition to the 34 existing questions. The question is "reasons for choosing an airline". Figure 1 illustrates reasons for choosing an airline (multiple-choice question).

Park et al. (2004) discovered that passengers' decisionmaking processes are directly affected by service value, passenger's satisfaction and airline image. In contrast, this survey shows that 49.7 per cent of passengers chose an airline because it offered 'discount (cheaper) tickets', 33.1 per cent of passengers focussed on 'high service quality', followed by 'safety and security reputation' (31.0\%).

It shows that a cheaper air ticket is the main reason for passengers' choice of airline, which takes precedence over service quality and safety.

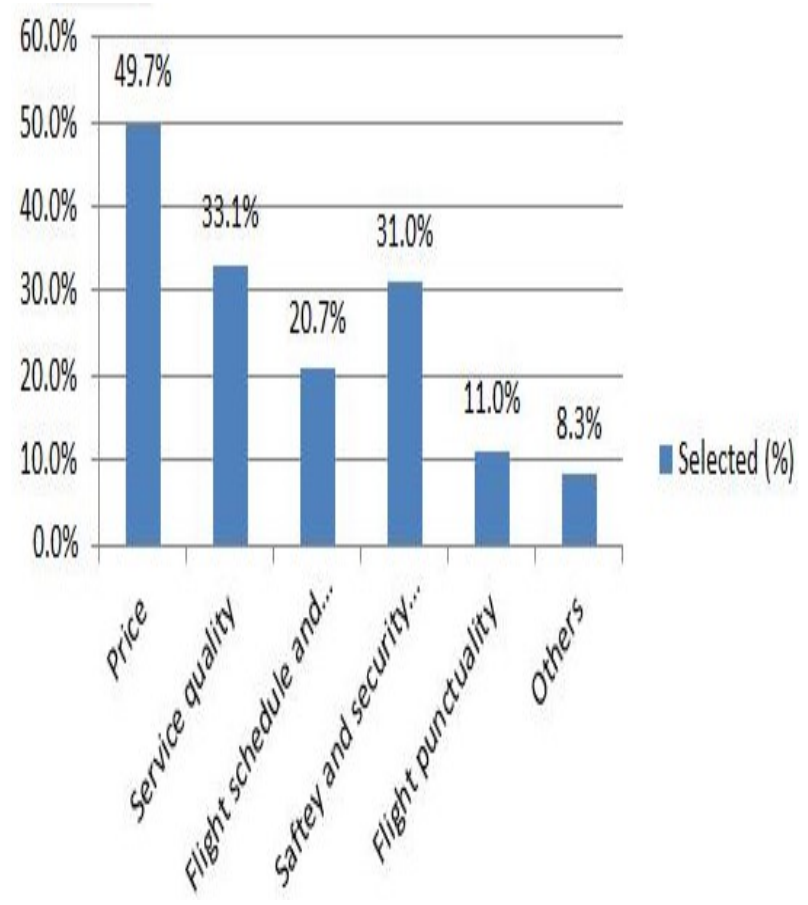

FIGURE 1. Reasons for choosing an airline 


\section{DISCUSSION}

According to the survey, the most common occupation for respondents in the sample is 'student' and the most common purposes for travel are 'holidays' and 'visiting friends and relatives'. This information indicates the major market demanders on the route from Australia to China are overseas students and leisure passengers. Therefore, the common selection of 'price' option in Figure 1 can be explained by the notion that overseas students and passengers travelling for leisure purposes are more sensitive to price when choosing an airline.

Although this study assesses passengers' perceptions of four Chinese airlines in order to compare in-flight service quality, it is interesting to compare the overall perceptions in terms of nationality. On average, Australians' annual income exceeds Asians', and working Australians are more entitled to holidays than workers in Asian countries. Thus, Australians have relatively greater opportunities to travel with airlines. The more airlines they fly with, the more sensitive their impressions of in-flight service quality become. Thus, their perceptions of in-flight service quality of Chinese airlines might build on a comparison with other international airlines, resulting in lower ratings as a result. As expected, the mean value for Australians' perceptions (3.34) is lower than that of Asians' (3.58), and the 1.4 percent of European passengers' perceptions is excluded from these results due to the very small sample size. Although ANOVA tests show that there are no significant differences of in-flight services between four airlines, some differences still exist. It is worthwhile to find out these differences.

\section{Cabin Configuration}

These four Chinese airlines are all using A330-200 aircraft on the route from Melbourne to China but with different configurations such as seat type, seat pitch, seat class, etc. The mean value of China Southern is lowest for each attribute related to seats. To understand why respondents perceived as such, some data were found from the Airlines' websites. For instance, the seat pitch is 32 inches for Air China and 29 inches for China Southern, and seat recline angles are 105 degrees for Air China and 100 degrees for China Southern (economy class), which demonstrates that China Southern sets a smaller seat space and backrest angle than Air China. As a result, the seating comfort, backrest angle, seat space and leg room are not satisfactory according to passengers flying with China Southern (China Southern, 2014; Air China, 2014). Passengers ranked Sichuan Airlines higher than the other three airlines in this section, but it also achieved the lowest mean value for its lighting condition. This may be due to the flight time. Sichuan Airlines only operates at night for flight from Melbourne to China, whereas Air China, China Eastern and China Southern all have flights which depart in the morning and arrive in the evening. In a night flight, passengers are more susceptible to lighting quality, and sleepless passengers who read or use electronic devices during night-lights may affect other passengers' perception of Sichuan Airlines' in-flight lighting condition.

\section{Entertainment Services}

In terms of entertainment services, China Eastern is ranked first for the attributes like screen size, operability of entertainment, audio quality, image quality, variety of games, movies update and flight information. In other words, passengers recorded a better experience of China Eastern's in-flight entertainment system than that of the other three airlines.

Nevertheless, 'variety of games' and 'movie update' seem in need of further improvement as the mean values are relatively low. Only the 'flight information' provided by Chinese Eastern can be labelled as satisfactory by passengers due to its mean value of 4.00. In contrast, Sichuan Airlines received the lowest perception score in this section. Although each seat in Sichuan Airlines is equipped with an entertainment system as in Air China, China Eastern and China Southern, passengers' perceptions are not the same for each airline. In addition, Sichuan Airlines is short of duty free sales. These may be because it is a new operator on the air route from Australia to China since 2014, and still requires time to understand customers' needs.

\section{Meals/Snacks}

In terms of meals/snacks, passengers preferred the food provided by Sichuan Airlines. Research shows that Sichuan Airlines customised in-flight meals to by spicy. As most people from Sichuan love spicy food and many passengers are from Sichuan, it explains why mean values of Sichuan Airlines are better than those of the other three airlines in terms of food options, food quality, presentation of food and special request.

Conversely, Air China ranked low for the same attributes. The mean values are just above 3 . During the process of survey collection, several respondents complained that their experiences with Air China were that the alcoholic beverage was out of supply within the first three hours of the flight. In order to have sustainable competitive strength in 
this market, Air China may need to implement improved in-flight meal services on the route from Australia to China.

\section{Flight Attendants' Service}

Passengers are satisfied with China Eastern in terms of quality of cabin announcement, promptness of service, proactivity of flight attendants and flight attendants' ability to handle customer complaints, as the mean values are all above 4. Consequently, China Eastern is ranked first in terms of its flight attendants' service. One factor requiring improvement is "consideration for passengers' needs and interests" however, as passengers gave a medium perception score for this attribute for China Eastern as well as the other three airlines. Sichuan Airlines has more room for improvement in terms of its flight attendants' service. Data in table 3 clearly show that for each attribute, passengers' perceptions of Sichuan Airlines are lower than those of the other three airlines. The reason behind this may be due to the operating duration. Sichuan Airlines started its first international flight in 2007 from China to Canada while the other three Chinese airlines have already operated many international flights for some time. In this sense, Sichuan Airlines can be defined as a new entrant, especially on the air route from Australia to China which has only been operated for less than two years.

\section{Nationalities}

Interesting comparisons may be drawn between passengers' overall perceptions in terms of nationality. On average, Australians' annual income is fairly higher than that of Chinese citizens, and they may also be more generously entitled to vacations. In this sense, there are more opportunities for Australians to travel with airlines relative to Chinese citizens. The more airlines they fly with, the more sensitive their perceptions of service quality become. Thus, their perceptions of the in-flight service quality of Chinese airlines might build on a comparison with other international airlines, and therefore result in a lower rating. As expected, the mean value of Australians' perceptions (3.34) is lower than that of Asians' (3.58), and the 1.4 percent of European perceptions is excluded from these results due to a very small sample size used.

\section{Reasons for Choosing an Airline}

According to the survey, $44.1 \%$ of passengers' income are less than $A \$ 20,000$ a year and the top two purposes of travel are holidays and VFR (visiting friends and relatives). The information indicates the major market demander on the route from Australia to China is overseas students and leisure passengers. Therefore, the common selection of the 'price' option in Figure 1 can be explained by the idea that low income and leisure passengers are more sensitive to price when choosing an airline.

\section{CONCLUSION}

This research investigates in-flight service among four Chinese airlines flying from Melbourne to China. To help airlines better understand how the customer views their services relative to their competitors, an evaluation of in-flight service quality based on passengers' perceptions has been presented. Although statistical tests show that there are no significant differences of in-flight services between the four airlines, some important points need to be considered by the industry. In regards to four aspects of in-flight service, the results show that firstly, passengers rank Sichuan Airlines higher than the other three airlines for cabin configuration. Secondly, passengers have a better experience of in-flight entertainment system with China Eastern than with the other three airlines. Thirdly, passengers prefer the food provided by Sichuan Airlines as spiciness has been added into in-flight meals, consistent with passengers' preferences.

Finally, China Eastern is ranked first in terms of its flight attendants' service among the four Chinese airlines. In terms of seat class, passengers are satisfied with the inflight service quality in business class provided by China Eastern, followed by China Southern and Sichuan Airlines. Passengers' perceptions of premium economy class operated by China Southern are higher than those of economy and business classes operated by the same airline. Moreover, the in-flight service quality of Air China, China Eastern and Sichuan Airlines in economy class is perceived as similar by passengers while China Southern garnered comparatively worse impressions. The evaluation outcome also provides a guideline for airlines to improve in-flight service quality in response to customers' needs. Air China may need to improve the quality of its in-flight meals; China Eastern may need to devote more time and attention to updating games and movies; China Southern has more room for improvement in any aspect of its in-flight service; Sichuan Airlines would benefit from enhancing its in-flight entertainment services and flight attendants' service. Meanwhile, passengers who plan to travel directly from Australia to China in the future are able to consider the results of this study as a reference. According to Clemes, Gan, Kao \& Choong (2008), passengers' perceptions of travel service 
quality have changed in this dynamic environment. Other important factors such as airfare or reliability also need to be considered. As a result, this research paper demonstrates that the most important factor that passengers consider when choosing an airline is 'cheaper airfare', not 'high service quality'. These results support previous research regarding the effect of price on passengers' choice of airline (Atalik, 2007; Jiang, 2003; Jiang, 2013; Nugraha \& Indrawati, 2017). They do not support research undertaken by Gilbert \& Wong (2003), Natalisa \& Suharto (2003) and Clemes et al. (2008), who suggested that 'safety' was the most important factor of consideration for passengers. It does not support findings from Gourdin, Gourdin \& Kloppenborg (1991) and Young, Cunningham \& Lee (1994) either, who contended that flight connections and in-flight comfort constituted the two most important dimensions, whereas the operations and safety dimensions constituted the least important factors. The results obtained in this research should provide information for carrier management to help them plan for further improvements in their service quality (Chow, 2014).

\section{RESEARCH LIMITATIONS AND FUTURE RESEARCH}

This study was limited to and mainly focuses only on the four Chinese Airlines flying from Melbourne to China. Therefore, the participants in this study were passengers who travelled with only these four airlines from Melbourne. The results of the study could be different if the study covered more respondents at other Australian airports such as Sydney airport and Brisbane airport. Consequently, further studies can be expanded to include more airports operating flights from Australia to China.

\section{REFERENCES}

Air China. 2014. Seat maps airbus A330, air China. URL: goo.gl/i7oGzo. Last accessed on 5 November 2014.

Alamdari, F. 1999. Airline in-flight entertainment: The passengers' perspective. Journal of Air Transport Management, 5(4): 203-209. DOI: 10.1016/S0969-6997(99)00014-9

An, M., \& Noh, Y. 2009. Airline customer satisfaction and loyalty: Impact of in-flight service quality. Service Business, 3(3): 293-307. DOI: 10.1007/s11628-009-0068-4

Australian Bureau of Statistics. 2014. Short term visitor arrivals from China have more than tripled since 2003-04. URL: goo.gl/KSMWC3. Last accessed on 31 August 2014.

Anderson, C.R., \& Zeithaml, C.P. 1984. Stage of the product life cycle. Business Strategy \& Business Performance, 27: 5-24. Atalik, 0. 2007. Comparing the factors affecting the choice of airlines for frequent flyers and non-frequent flyers: Case of Turkish air travellers. Paper presented at the Ninth International Conference of The Global Business and Te chnology Association (GBATA), Taipei, TW.

Buzzell, R., \& Gale, B. 1987. The PIMS principles. New York; NY: The Free Press.

Chang, Y. H., \& Yeh, C.H. 2002. A survey analysis of service quality for domestic airlines. European Journal of Operational Research, 139(1): 166-177. DOI: 10.1016/S0377-2217(01)00148-5

Cheaosakul, W. 2004. Consumers' perception of service quality: A case study of Thai airways international plc. UnpubMBA thesis, Assumption University, Bangkok, TH.

Chen, F. Y., \& Chang, Y. H. 2005. Examining airline service quality from a process perspective. Journal of Air Transport Man- agement, 11(2): 79-87. DOI: 10.1016/j.jairtraman.2004.09.002

Chen, Y.H., Tseng, M.L., \& Lin, R.J. 2011. Evaluating the customer perceptions on in-flight service quality. African Journal of Business Management, 5(7): 2854-2859.

China Southern Airlines. 2014. Cabin layout, China southern airlines. URL: goo.gl/URxll0. Last accessed on 5 November 2014.

China Southern Airlines. 2011. China southern airlines initiates the first domestic flight to perth-capital of Western Australia, China Southern airlines. URL: goo.gl/P9oObZ. Last accessed on 5 November 2014.

Cronin Jr, J.J., \& Taylor, S.A. 1992. Measuring service quality: A reexamination and extension. The Journal of Marketing, 56(3): 55-68. DOI: $10.2307 / 1252296$

Chou, C.C., Liu, L.J., Huang, S.F., Yih, J.M., \& Han, T.C. 2011. An evaluation of airline service quality using the fuzzy weighted servqual method. Applied Soft Computing, 11(2): 2117-2128. D0I: 10.1016/j.asoc.2010.07.010

Chow, C.K.W. 2014. Customer satisfaction and service quality in the Chinese airline industry. Journal of Air Transport Man- agement, 35: 102-107. DOI: 10.1016/j.jairtraman.2013.11.013 
Clemes, M.D., Gan, C., Kao, T.H., \& Choong, M. 2008. An empirical analysis of customer satisfaction in international air travel. Innovative Marketing, 4(2): 50-62.

Elliott, K.M., \& Roach, D.W. 1993. Service quality in the airline industry: Are carriers getting an unbiased evaluation from consumers? Journal of Professional Services Marketing, 9(2): 71-82. D0I: 10.1300/J090v09n02_06

Gale, T. B. 1992. Monitoring customer satisfaction and market perceived quality. Chicago, IL: American Marketing Assotion.

Garvin, D.A. 1983. Quality on the line. Harvard Business Review, 61 (5): 64-75.

Gerbing, D.W., \& Anderson, J.C. 1988. An updated paradigm for scale development incorporating unidimensionality and its assessment. Journal of Marketing Research, 25(2): 186-192. DOI: 10.2307/3172650

Gilbert, D., \& Wong, R.K. 2003. Passenger expectations and airline services: A Hong Kong based study. Tourism Manage- ment, 24(5): 519-532. DOI: 10.1016/S0261-5177(03)00002-5

Gourdin, K.M., Gourdin, K.N., \& Kloppenborg, T.J. 1991. Identifying service gaps in commercial air travel: The first step to- $\quad$ ward quality improvement. Transportation Journal, 31(1): 22-30.

Grönroos, C. 1984. A service quality model and its marketing implications. European Journal of Marketing, 18(4): 36-44. DOI: $10.1108 /$ EUM0000000004784

Hair, J.H., Anderson, R.E., Tatham, R.L., \& Black, W.C. 1998. Multivariate data analysis. Upper Saddle River, NJ: Prentice Hall, Inc.

Huang, Q.G. 2014. Agricultural cooperation: New highlight in the development of China-Australia trading tie, ministry of foreign affairs of the People's Republic of China, Perth, 10 April. URL: goo.gl/1NEKi5. Last accessed on 31 August 2014.

Jiang, H. 2013. An investigation of airline service quality and passenger satisfaction the case of China eastern airlines in Wuhan region. International Journal of Aviation Management, 2(1-2): 54-65. DOI: 10.1504/IJAM.2013.053048

Jiang, H. 2003. Internet economy and Chinese airline industry. Paper presented at the 15th Annual Conference of the Association for Chinese Economics Studies Australia (ACESA), Melbourne, AU.

Kotler, P. 2000. Marketing management: The millennium. New Jersey, US: Prentice Hall.

Natalisa, D., \& Subroto, B. 2003. Effects of management commitment on service quality to increase customer satisfaction of domestic airlines in Indonesia. Singapore Management Review, 25(1): 85-89.

Na Ayutthaya, J.S., Tuntivivat, S., \& Prasertsin, U. 2016. The effect of positive psychological capital and organizational climate on service quality: The mediation role of work engagement of hotel service employees in Ratchaburi province. Journal of Administrative \& Business Studies, 2(4): 167-176.

Nugraha, P.A., \& Indrawati. 2017. The effect of social media experiential marketing towards customers' satisfaction (A study in Chingu Korean fan cafe Bandung Indonesia). International Journal of Business \& Administrative Studies, 3(2): 56- 63.

Nunnally, J., \& Ira, B. 1994. Psychometric theory. New York, NY: McGraw-Hill.

Ostrowski, P. L., O'Brien, T.V., \& Gordon, G.L. 1993. Service quality and customer loyalty in the commercial airline industry.

Journal of Travel Research, 32(2): 16-24. DOI: 10.1177/004728759303200203

Oyewole, P. 2001. Consumer's socio-demographic characteristics and satisfaction with services in the airline industry. Ser- vices Marketing Quarterly, 23(2): 61-80. DOI: 10.1300/J396v23n02_04

Pakdil, F., \& Aydın, Ö. 2007. Expectations and perceptions in airline services: An analysis using weighted servqual scores.

Journal of Air Transport Management, 13(4): 229-237. DOI: 10.1016/j.jairtraman.2007.04.001

Park, J.W., Robertson, R., \& Wu, C.L. 2004. The effect of airline service quality on passengers' behavioural intentions: A Ko- $\quad$ rean case study. Journal of Air Transport Management, 10(6): 435-439. D0I: 10.1016/j.jairtraman.2004.06.001

Phillips, L.W., Chang, D.R., \& Buzzell, R.D. 1983. Product quality, cost position and business performance: A test of some key hypotheses. The Journal of Marketing, 47(2): 26-43. D0I: 10.2307/1251491

Rigg, K. 2015. Increased flights announced between China \& Australia. URL: goo.gl/bFC7V9. Last accessed on 31 August 2014. 
Skytrax, D. 2014. The world's top 100 airlines in 2014. URL: goo.gl/DukZMp. Last accessed on 31 August 2014.

Taylor, S.A. 1993. The roles of service quality, consumer satisfaction, and value in Quinn's (1992) paradigm of services. Jour- ～nal of Marketing Theory \& Practice, 2(1): 14-26. D0I: 10.1080/10696679.1993.11501636

Young, C., Cunningham, L., \& Lee, M. 1994. Assessing service quality as an effective management tool: The case of the airline industry. Journal of Marketing Theory \& Practice, 2(2): 76-97. D0I: 10.1080/10696679.1994.11501652

— This article does not have any appendix. - 